\section{POR FUERA DE LA CASA DEL AMO Insumisión epistémica o cimarronismo intelectual en el pensamiento educativo afrocolombiano siglo $\mathrm{XX}$}

\author{
Jorge Enrique García Rincón
}

Desde sus primeras palabras este libro se convierte en referente analítico sobre el pensamiento y la educación afrocolombiana, un recorrido sobre el proceso histórico de construcción del pensamiento en el ámbito educativo, los más valiosos aportes críticos y políticos hechos a lo largo del siglo $\mathrm{xx}$ por líderes de la comunidad negra.

El corpus temático se encuentra organizado en cuatro grandes capítulos que abordan temas como: de la invisibilidad epistémica a la insumisión del negro en Colombia, capítulo dedicado a medir el pulso de las experiencias significativas de proclamación de un nuevo pensamiento cargado de identidad y búsqueda de la libertad del pueblo negro. Un segundo capítulo nos acerca al pensamiento educativo afrocolombiano los precursores del siglo XX, intelectuales dedicados a resaltar la episteme de las comunidades afro, reflexionar $\mathrm{y}$ hacer de sus experiencias una vos de libertad para el mundo. Tras reflexiones y evocación de sentido y pensamiento raizal se expone un tercer capitulo las experiencias educativas del movimiento social afrocolombiano, un pincelazo sobre las experiencias colectivas en instituciones educativas que toman de relieve un pensamiento propio, que conlleva como fin enaltecer una cultura minimizada por las imposiciones educativas estatales. Por último un cuarto capítulo nos lleva a entender la aplicación del campo epistémico en el pensamiento educativo afrocolombiano: otros pensadores y eventos del movimiento social, resaltando el conocimiento gestado en el siglo XX por intelectuales dedicados a crear un cambio trascendental para el pueblo negro.

La inspiración latente en cada línea de esta obra son los significativos encuentros y reivindicaciones del pensamiento de las comunidades negras desde la mima diáspora africana en los diferentes escenarios: tanto educativos como sociales en donde se debate una ideología arraigado en la sangre de esta raza, conquistando en cada uno de ellos una insumisión epistémica. Así mismo se expone la postura de varios intelectuales sobre Educación en sus aspectos socioculturales e individuales, así como la dialéctica del proceso de identidad política y los sistemas educativos prestablecidos por la hegemonía del estado social colombiano. 
Un aporte significativo en su género, y de indiscutible relevancia en el conjunto de diversidad epistémica. Un Trabajo, completo y riguroso, que ofrece también un panorama crítico sobre las adversidades y luchas, al mismo tiempo que cada aparte de esta obra relata la perseverancia por la reivindicación de las comunidades afrodescendientes una mirada sobre los devenires sociales: cada capítulo expone, la expresión de una ideología que busca cambiar poderes preestablecido en la escuela para darle espacio a la subjetividad de los pueblo negros. Siendo este es el eje sobre el que articula su amplia revisión de los principales autores contemporáneos, para cuya revisión el autor recurre al reconocimiento de la cultura en las tradiciones analíticas, problemas y desarrollos significativos del pensamiento de cada líder de la comunidad, a fin de poner de manifiesto lo arbitrario en el sistema oficial, para a partir de este análisis crear un diálogo necesario entre lo establecido y lo realmente necesario para las comunidades como la afrodescendiente, y lo importante de cimentar esta cultura dentro de los imaginarios y subjetividades de la sociedad contemporánea.

Por último el autor asume una visión general sobre los pilares del pensamiento educativo afrocolombiano, reflexionando sobre los puntos claves del desarrollo del pensamiento educativo, la apropiación de la cultura y la construcción colectiva de una identidad política.

Adriana Mabel Betancourt Bejarano

Magister en Educación

Universidad de Nariño 